\title{
Real-life burden of adverse reactions to biological therapy in inflammatory bowel disease: a single- centre prospective case series
}

Department of Health Sciences, University "Magna Græcia" of Catanzaro, Italy

DOI: $10.15386 / \mathrm{mpr}-1897$

Manuscript received: 16.09 .2020

Received in revised form: 20.02 .2021

Accepted: 15.03.2021

Address for correspondence:

tiziana.larussa@gmail.com

This work is licensed under a Creative Commons Attribution-NonCommercialNoDerivatives 4.0 International License
Tiziana Larussa, Antonio Basile, Caterina Palleria, Chiara Iannelli, Ada Vero, Lidia Giubilei, Caterina De Sarro, Evelina Suraci, Raffaella Marasco, Maria Imeneo, Emilio Russo, Ludovico Abenavoli, Giovambattista De Sarro, Francesco Luzza

\begin{abstract}
Background/aim. Biologics represent a key therapeutic option in inflammatory bowel disease (IBD), but are associated with several side effects. Post-marketing surveillance, through a spontaneous adverse drug reactions (ADRs) monitoring system, is essential to assess the safety profile of biologics. The aim of the study was to prospectively evaluate the occurrence of ADRs in IBD patients treated with biologics from a single centre in Southern Italy.

Methods. Data from patients with Crohn's Disease (CD) and Ulcerative Colitis (UC) who underwent biological therapy were prospectively collected. ADRs were classified according to the Medical Dictionary for Regulatory Activities (MedDRA®).

Results. Overall, 68 (54\% male, 68\% with UC and 32\% with CD) biologic-naïve IBD patients underwent biological therapy. Mean follow-up was $11.7 \pm 6.2$ months. As a results of switches, for 68 patients we obtained 96 biologic prescriptions. Overall, 45 ADRs occurred in 36 (53\%) patients, distributed as follows (ADRs/ prescriptions): $19 / 37$ with IFX-Remicade, $5 / 12$ with IFX-Remsima, $8 / 9$ with GOL, 11/26 with ADA, and 2/12 with VDZ. Mild ADRs were 29 (64\%), moderate 15 $(34 \%)$ and $1(2 \%)$ severe. General disorders and administration related reactions were the most frequent ADRs (35\%), followed by skin and subcutaneous tissue disorders $(20 \%)$, infections $(15 \%)$, musculoskeletal $(11 \%)$, respiratory $(6 \%)$ blood (4\%), gastrointestinal (4\%), and vascular disorders $(2 \%)$. In 9 cases $(20 \%)$ the ADRs resulted in definitive discontinuation of biologic therapy.

Conclusion. In a prospective cohort of IBD patients, more than half experienced ADRs during biologic therapy. General disorders and administration related reactions were the most common ADRs, while infections were less common and rarely led to discontinuation of therapy. Findings underline the importance of surveillance in management of IBD patients during biologic therapy and implementing safety protocols with data from real-life settings.
\end{abstract}

Keywords: inflammatory bowel disease, adverse drug reactions, TNF inhibitors, pharmacovigilance, drug safety, biological therapy 


\section{Introduction}

Over the last 20 years, the introduction of biologics represented a breakthrough in the management of inflammatory bowel diseases (IBD), as a fundamental therapeutic option in patients not responding to conventional therapies (mesalamine, steroids and immunosuppressants). The goal of medical therapy is to induce and maintain clinical, endoscopic and histological remission; however, significant challenges remain, including maintaining the long-term therapeutic response, avoiding treatment toxicity and preventing the progression of disease [1].

A tailored therapy is the key for an optimal management of IBD, based on a balance of the riskbenefit profile, clinical judgment and patient preferences [2]. Biological drugs are characterized by improved selectivity compared with conventional therapy, since they act on inflammation mediators, such as TNF- $\alpha$, and on the binding of lymphocytes to the intestinal epithelium [3]. Besides the clinical benefit, toxicity is the main concern for these drugs and continuous pharmacovigilance programs regarding surveillance for adverse drug reactions (ADRs) from biologics need to be implemented [4]. Clinicians should be aware of potential risks and recognize side effects that may result from the use of these drugs. Clear management strategies in different scenarios are also desirable [5]. The most common ADRs described for biologics are infections, malignancies, immunogenicity, and metabolic disorders [6]. Paradoxical inflammatory effects of TNF- $\alpha$ inhibitors have also been described and include exacerbation or initiation of druginduced autoimmune diseases, such as psoriasis, systemic lupus erythematosus, vasculitis and uveitis [7]. Most of the data come from clinical trials, which use rigorous inclusion criteria, and thus may not reflect what is found in real clinical practice. Indeed, clinical trials often report short-term clinical outcomes and primary endpoint aims mostly relating to drug effectiveness and not to detailed ADRs description. Research into the long-term safety of biologics needs to be implemented, as well as comparative safety reports for different biologics, and national registries could be used for further relative safety of biologics assessment [8].

The aim of this study was to prospectively describe, in a real-life context, the occurrence and the type of ADRs in a case series of IBD patients from Southern Italy undergoing biological therapy. We considered infliximab, adalimumab, golimumab and vedolizumab since they are used for both Crohn's disease (CD) and ulcerative colitis (UC). A variety of abbreviations for each of the monoclonal antibodies is present in scientific literature, so we chose the most used abbreviation in Italy as follows: IFX for infliximab, ADA for Adalimumab, GOL for Golimumab and VDZ for Vedolizumab.

\section{Material and methods \\ Patients}

In the period between February 2017 and January 2020, consecutive biologic naïve patients with CD and UC, who were candidates for biological therapy at the Digestive Physiopathology Unit of the "Mater Domini" University Hospital, were enrolled prospectively in order to obtain a case series. Diagnosis of UC and CD was established according to clinical, endoscopic and histological criteria [9]. Patient characteristics, medical history, and concomitant medications were extracted from the patients' medical records and confirmed with the patient during their on-site visit. The following data were collected: age, sex, type and duration of disease, current medication, previous use of anti TNF- $\alpha$ agent or other biologic drugs, and presence of other relevant co-morbidities. Patients with previous use of biologic for IBD or any other medical condition were excluded.

\section{Pre-biological screening}

Before biologic therapy began, all patients in the study population underwent a pre-biological screening, according to an internal protocol. Each patient for biological therapy was subjected to routine serological tests, such as complete blood count, chemistry panel and coagulation parameters. All patients underwent microbiological (IGRA test) and radiological (chest X-ray) tests to rule out the presence of latent tuberculosis infection. Virologic tests were performed to rule out the presence of latent viral infections (Table I). Pregnancy status in women of childbearing potential was assessed by measuring the $\beta$-HCG hormone in urine and serum.

Table I. Virological panel for pre-biological screening performed in the study population.

$\begin{array}{ll}\text { Virus } & \text { Test } \\ \text { HBV } & \text { HBsAg, Anti HBs, Anti HBc } \\ \text { HCV } & \text { Anti HCV antibodies } \\ \text { Rubella } & \text { IgM antibodies } \\ & \text { IgG antibodies } \\ \text { CMV } & \text { Anti CMV IgM antibodies } \\ & \text { Anti CMV IgG antibodies } \\ \text { Herpes Virus } & \text { Anti Herpes simplex 1+2 IgM antibodies } \\ \text { Varicella Zoster } & \text { Anti Herpes simplex 1 + 2 IgG antibodies } \\ \text { Virus } & \text { Anti Varicella Zoster virus IgM antibodies } \\ \text { Measles } & \text { Anti Measles IgM antibodies } \\ & \text { Anti Measles IgG antibodies } \\ \text { EBV } & \text { Anti EBV-VCA IgM antibodies } \\ & \text { Anti EBV-VCA IgG antibodies } \\ \text { HIV } & \text { Anti HIV 1/2 } \\ & \text { P24 Antigen } \\ \text { HBV= Hepatitis } & \text { B Virus; HCV= Hepatitis C Virus; CMV= } \\ \text { Citomegalovirus; } & \text { EBV = Epstein Barr Virus; HIV = Human } \\ \text { Immunodeficiency } & \text { Virus. }\end{array}$




\section{Method of administration}

Infliximab (IFX-Remicade or IFX-Remsima) was administered as an intravenous infusion at the dose of 5 $\mathrm{mg} / \mathrm{kg}$, followed by an additional infusion of $5 \mathrm{mg} / \mathrm{kg} 2$ weeks later and 4 weeks later, during the induction phase. During the maintenance phase, an infusion of $5 \mathrm{mg} / \mathrm{kg}$ of IFX was performed every 8 weeks. Adalimumab (ADA) was administered subcutaneously at the standard dose of $160 \mathrm{mg}$ followed by a dose of $80 \mathrm{mg}$ after 2 weeks, during the induction phase, and then the patient received $40 \mathrm{mg}$ every other week during the maintenance phase. Golimumab (GOL) was administered subcutaneously at an initial 200 $\mathrm{mg}$ dose, followed by $100 \mathrm{mg}$ at week 2 in the induction phase. During maintenance phase, patients received $100 \mathrm{mg}$ or $50 \mathrm{mg}$ every 4 weeks, as per their body weight $\geq$ or $<$ $80 \mathrm{~kg}$, respectively. Vedolizumab (VDZ) was administered intravenously in a dose of $300 \mathrm{mg}$, followed by an additional infusion of the same dose 2 weeks later and 4 weeks later, during the induction phase. In the maintenance phase, patients underwent infusions at $300 \mathrm{mg}$ dose every 8 weeks. Intravenous administration was performed on site, while subcutaneous administration was managed by the patients after nursing training at the site. Patients' vital signs including blood pressure, cardiac frequency and body temperature were obtained prior to, during, and at completion of infusion. After infusion, patients were monitored by an experienced nurse for a minimum of 60 minutes after the first 3 infusions and a minimum of 30 minutes after each maintenance infusion. The nurse was trained to observe for any infusionrelated adverse events and to seek medical attention if any ADR occurred, as well as to manage the situation according to the internal protocol. For IFX only, an oral pre-medication with loratadine $(10 \mathrm{mg}$ ) was administered to the patient. No dose adjustment was performed other that described above in any of the patients.

\section{Adverse events classification}

Safety was assessed at each treatment visit by ADR evaluation, clinical laboratory tests, and physical examinations, and obviously through prompt reporting of the patient when an ADR occurred. A trained physician filled in the suspected ADR reporting form of the Italian Medicines Agency (Agenzia Italiana del Farmaco, AIFA) recording a detailed description, including time of onset and recovery, severity, and outcome. Pharmacologists' team codified the ADRs according to the Medical Dictionary for Regulatory Activities (MedDRA ${ }^{\circledR}$, The International Federation of Pharmaceutical Manufactures \& Associations, IFPMA, Geneva, Switzerland), Preferred Term (PT) and System Organ Class (SOC) levels. All those events that occurred in the first 24 hours from administration were defined early, and those that occurred after 24 hours and within 14 days were defined late ${ }^{[10]}$. ADRs which caused minimal discomfort and did not interfere with normal daily activities were defined mild, while ADRs that caused discomfort to the patient, hindering the normal course of daily activities, were defined as moderate. An ADR was defined as serious if it was life-threatening or fatal, or required hospitalization (or prolonged existing hospitalization), or resulted in persistent or significant disability or in a congenital anomaly/birth defect, or consisted of any other medical relevant condition [11]. Infusion-related reactions (IRRs) were considered as those ADRs that occurred during the administration of an intravenous biologic agent or within the following two hours from termination [12].

\section{Protocols adopted in case of infusion-related} reactions at site

Since the intravenous administration of biologic agents were performed only on site, all the IRRs were recorded during the procedure, in the presence of the nurse and the medical staff. In mild ADRs, the infusion rate was reduced to $10 \mathrm{~mL} / \mathrm{h}$ and chlorphenamine $(10$ $\mathrm{mg} / 1 \mathrm{ml}$ intravenously) and paracetamol $(650 \mathrm{mg})$ were administered, followed by physiological solution for infusion from $500 \mathrm{~mL} / \mathrm{h}$ to $1000 \mathrm{~mL} / \mathrm{h}$. The vital signs were monitored every 10 minutes, until they returned to normal limits. In patients stabilized with the treatment described above, the infusion was resumed at $10 \mathrm{~mL} / \mathrm{h}$ for 15 minutes, then increased to $20 \mathrm{~mL} / \mathrm{h}$ for 15 minute, then 40 $\mathrm{mL} / \mathrm{h}, 80 \mathrm{~mL} / \mathrm{h}, 100 \mathrm{~mL} / \mathrm{h}$ and finally $125 \mathrm{~mL} / \mathrm{h}$ every 15 minutes, if tolerated. In moderate ADRs, the infusion was stopped and chlorphenamine (10 $\mathrm{mg} / 1 \mathrm{ml}$ intravenously) and paracetamol $(650 \mathrm{mg})$, were administered followed by physiological solution for infusion from $500 \mathrm{~mL} / \mathrm{h}$ to $1000 \mathrm{~mL} / \mathrm{h}$. In severe ADRs, the infusion was stopped and chlorphenamine $(10 \mathrm{mg} / 1 \mathrm{ml})$, hydrocortisone (100 $\mathrm{mg}$ ) or methylprednisolone $(20-40 \mathrm{mg}$ ) were administered intravenously plus physiological solution for infusion (500$1000 \mathrm{~mL} / \mathrm{h}$ ). Adrenaline (1: 1000) syringe from $0.1 \mathrm{~mL}$ to $0.5 \mathrm{~mL}$ were available to be used subcutaneously.

\section{Ethical considerations}

The study protocol was approved by the local Ethics Committee (Comitato Etico Regionale Calabria, Italy), protocol number 278/2015. Written informed consent was obtained from all patients at the time of enrollment. Patients were informed that medical records utilized for this study will remain anonymous. All procedures were performed in accordance with the 1964 Declaration of Helsinki and its later amendments.

\section{Results \\ Demographic and clinical characteristics of the study population}

During the period of the study, a total of 71 biologicnaïve consecutive patients with IBD underwent biological therapy. Of them, 68 (37 male and 31 female), of which 46 (68\%) were UC and 22 (32\%) CD patients, accepted to take part in the prospective study. Patients with UC displayed a pancolitis in the majority $(n=31,67.5 \%)$ of cases, while $C D$ patients showed an ileo-colonic involvement in $16(73 \%)$ cases. During the study period, 46 patients experienced one 
single type of biological drug, while for 18 patients it was necessary to switch to a second type of biologic (5 patients withdrew drug because of ADRs, 13 because of loss of response), and in 5 patients, it was necessary to use a third type after the failure of the two previously used. Therefore, for 68 patients we registered 96 biologic prescriptions and we considered this number for the analysis of the ADRs. No patient had significant heart failure, neurological pathologies, chronic liver diseases or a clinical history of lymphoproliferative diseases. No patient had previously been treated with biologics, nor had been taking thiopurines or steroids when initiating biologics. All patients had been on a stable dose of oral mesalazine for at least 6 months.

The demographic and clinical characteristics of the patients, according to biologic therapy, are shown in table II.

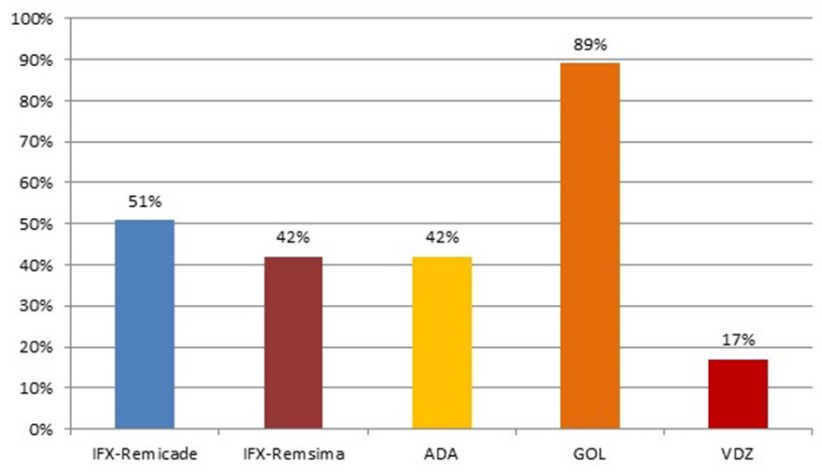

Figure 1. Incidence rate of the ADRs according to the number of prescriptions for each drug (19/37 with IFX-Remicade, 5/12 with IFX-Remsima, 8/9 with GOL, 11/26 with ADA, and 2/12 with VDZ).

Occurrence of the adverse drug reactions

Among the 96 prescribed treatments, a total of 45 ADRs occurred in 36 (53\%) patients, as follows: 19 ADRs with IFX-Remicade, 5 with IFX-Remsima, 8 with GOL, 11 with ADA, and 2 with VDZ. Considering that the 96 prescriptions were differently distributed (IFX-Remicade $\mathrm{N}=37$, IFX-Remsima $\mathrm{N}=12$, ADA $\mathrm{N}=26$, GOL N=9, VDZ $\mathrm{N}=12$ ), we evaluated the incidence rate of ADRs for each drug, comparing the number of ADRs that occurred for each biologic with the corresponding number of treatments for that biologic. Although in terms of absolute numbers the majority of the ADRs occurred during IFXRemicade, GOL showed the worst safety performance, as for 9 prescriptions there were 8 ADRs (Figure 1).

\section{Description of the adverse drug reactions}

Among the 45 ADRs, 16 (36\%) were early and $29(64 \%)$ late ADRs, while according to severity we found 29 (64\%) mild ADRs, 15 (34\%) moderate ADRs and only $1(2 \%)$ severe ADR. Among the early ADRs, the most common were the IRRs $(\mathrm{N}=9,20 \%)$, which occurred with heterogeneous symptoms and signs, such as flushing, dyspnea, cough, bronchospasm, sense of chest constriction, hypertensive spikes, nausea, headache, rash, and dizziness. Such reactions were reported in 7 patients taking IFX-Remicade and 2 patients taking IFX-Remsima, while no VDZ infusion was accompanied by IRRs. Of the IRRs, 4 occurred in the induction phase, and 5 between the fourth and tenth administration, over an average period of 8 months. In 3 cases, the occurrence of IRRs made it necessary to discontinue the infusion. Relevant late ADRs were infections, represented by 7 ADRs and including bacterial and fungal infections as well as herpes virus reactivation. Of note, 2 cases of leukopenia occurred, one following the fifteenth administration of ADA, and one after the fourth administration of IFX-Remsima. Both these ADRs led to the definitive discontinuation of the drug. Detailed information of the ADRs, provided as a MedDRA $\AA$ compliant description, are summarized in table III.

Table II. Clinical and demographic characteristics of the 68 patients with IBD according to each biologic drug used (N=96 prescriptions*).

\begin{tabular}{|c|c|c|c|c|c|c|}
\hline & IFX/RC & IFX/RS & ADA & GOL & VDZ & Total \\
\hline Prescriptions & $\mathbf{N}=\mathbf{3 7}$ & $\mathbf{N}=12$ & $\mathbf{N}=\mathbf{2 6}$ & $\mathbf{N}=\mathbf{9}$ & $\mathbf{N}=\mathbf{1 2}$ & $\mathrm{N}=96$ \\
\hline Age at starting therapy, years (mean \pm SD) & $41.6 \pm 13.9$ & $44.1 \pm 12.1$ & $43.5 \pm 13.5$ & $40 \pm 10.8$ & $43.4 \pm 18.4$ & $43 \pm 13.7$ \\
\hline $\operatorname{Sex}(\mathbf{M} / \mathbf{F})$ & $18 / 19$ & $8 / 4$ & $10 / 16$ & $5 / 4$ & $5 / 7$ & $46 / 50$ \\
\hline $\begin{array}{l}\text { Type of disease } \\
\text { UC } \\
\text { CD }\end{array}$ & $\begin{array}{l}24 \\
13\end{array}$ & $\begin{array}{l}9 \\
3\end{array}$ & $\begin{array}{l}12 \\
14\end{array}$ & $\begin{array}{l}9 \\
0\end{array}$ & $\begin{array}{c}10 \\
2\end{array}$ & $\begin{array}{l}64 \\
32\end{array}$ \\
\hline $\begin{array}{l}\text { Duration of disease at starting therapy, } \\
\text { years (mean } \pm \text { SD) }\end{array}$ & $13.2 \pm 7.4$ & $11.1 \pm 8.5$ & $14.6 \pm 7.4$ & $12.3 \pm 7.7$ & $12.1 \pm 7.2$ & $12.9 \pm 7.3$ \\
\hline $\begin{array}{l}\text { Duration of therapy or last follow-up, } \\
\text { months (mean } \pm \text { SD) }\end{array}$ & $11.8 \pm 7.2$ & $8.7 \pm 5.1$ & $13.6 \pm 8$ & $12.7 \pm 6.6$ & $7.8 \pm 4.2$ & $11.7 \pm 6.2$ \\
\hline
\end{tabular}

$* \mathrm{~N}=23$ patients underwent therapy with more than one biological drug

$\mathrm{SD}=$ standard deviation, $\mathrm{UC}=$ ulcerative colitis, $\mathrm{CD}=$ Crohn disease, IFX/RC $=$ Infliximab Remicade, IFX/RS $=$ Infliximab $\mathrm{Remsima}$, $\mathrm{ADA}=$ Adalimumab, $\mathrm{GOL}=$ Golimumab, $\mathrm{VDZ}=$ Vedolizumab 
In total, $9(20 \%)$ ADRs resulted in definitive discontinuation of the drug in 9 patients. Except for one, classified as severe IRR which required hospitalization of the patient, the remaining 8 were of a moderate type
(Table IV). No ADRs resulted in the patient's death or the occurrence of permanent disabilities. Furthermore, there have been no cases of malignancy during the observed period.

Table III. MedDRA ${ }^{\circledR}$ compliant description of adverse drug reactions.

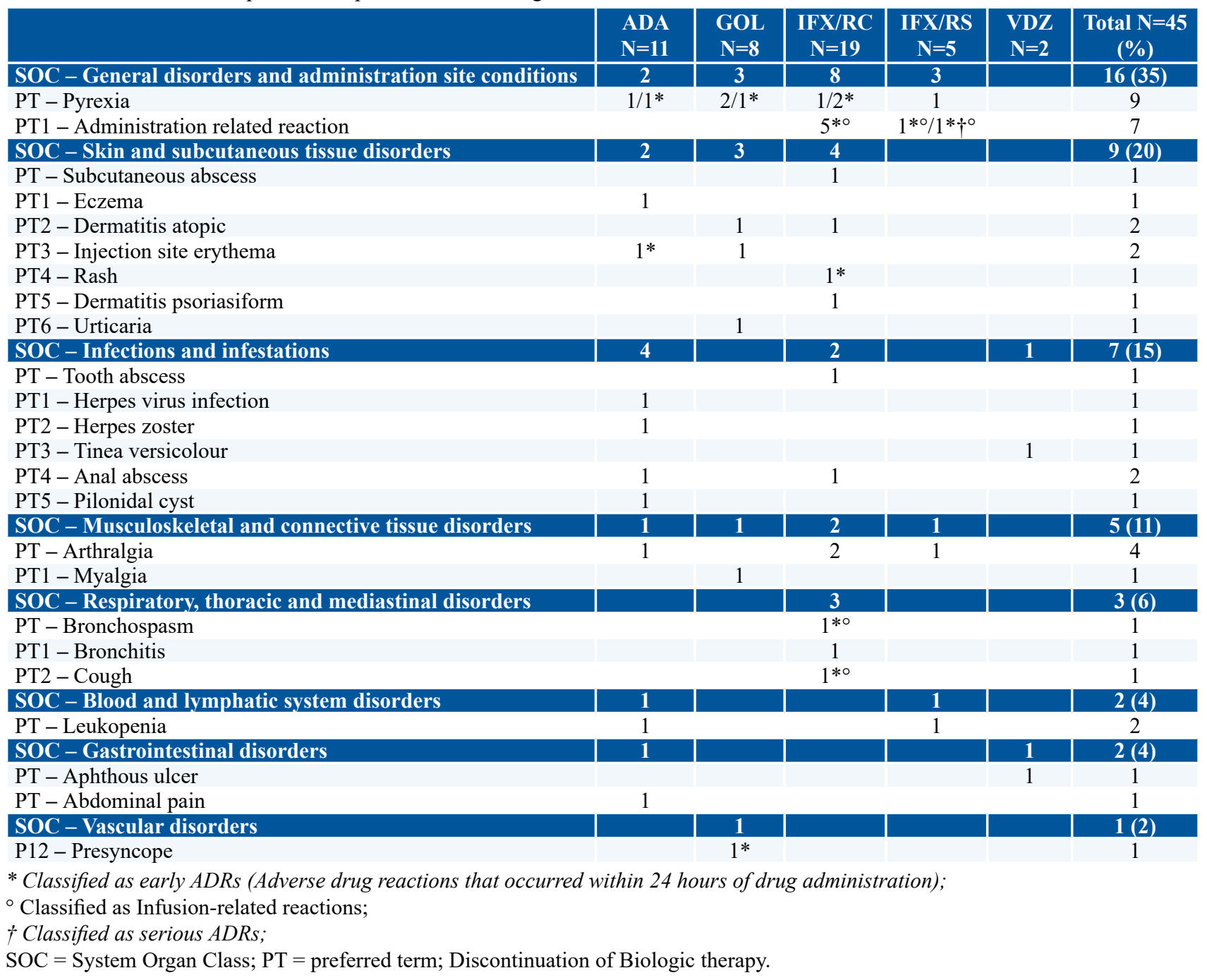

Table IV. Adverse drug reactions that led to discontinuation of therapy.

\begin{tabular}{|c|c|c|c|c|}
\hline ADRs (case) & Characteristics of the patient & ADR type & Drug & $\begin{array}{l}\text { Duration therapy at the time of } \\
\text { the ADR, months }\end{array}$ \\
\hline 1 & male; UC; 17 years & IRR & Remicade & 1.5 \\
\hline 2 & male; $C D ; 35$ years & IRR & Remicade & 0.5 \\
\hline 3 & male; UC; 25 years & IRR & Remsima & 8 \\
\hline 4 & female; UC; 47 years & Vasovagal syncope & Golimumab & 0 \\
\hline 5 & female; UC; 62 years & Herpetic dermatitis & Adalimumab & 22 \\
\hline 6 & female; CD; 33 years & Skin abscess & Remicade & 16 \\
\hline 7 & female; CD; 27 years & Skin abscess & Adalimumab & 13 \\
\hline 8 & female; UC; 36 years & Leukopenia & Adalimumab & 8 \\
\hline 9 & male; CD; 50 years & Leukopenia & Remsima & 12 \\
\hline
\end{tabular}

$\mathrm{UC}=$ ulcerative colitis; $\mathrm{CD}=\mathrm{Crohn}$ disease; IRR $=$ infusion-related reaction. 


\section{Discussion}

Biological drugs have radically changed the management of patients with CD and UC. Beyond their proven effectiveness, however, doubts remain regarding their safety profile and the optimization of their use, especially in relation to an individualization of the therapy [13]. In our case series, the occurrence of ADRs during biological therapy was assessed in 68 consecutive patients with IBD, during a two-year period. We registered 45 ADRs out of a total of 96 treatments. This result is substantially in line with current literature, although it is not easy to obtain an estimate of the incidence of ADRs as the studies are conditioned by the characteristics of the population under consideration, by the study design, as well as by the classification criteria of the ADRs [14].

The incidence of the ADRs in our case series have confirmed that the safety of IFX-Remsima is comparable to that of the originator, as previously reported [15]. Accordingly, VDZ seemed to display the better safety profile in our cohort, as demonstrated in other multicenter experience [16]. Of note was the number of ADRs observed with GOL (8 among 9 treatments), although they did not determine discontinuation of the drug. GOL was recently the subject of an Italian multicenter prospective study that assessed its efficacy and safety in a real-life context, and the final analysis showed that the ADRs caused by GOL were $4 \%$ and all were dermatological reactions occurring at the injection site [17]. Our data were probably affected by the very small number of patients under GOL treatment.

General disorders and administration site conditions, such as acute hypersensitivity reactions (the so-called IRRs), injection site swelling and induration, and fever, are among the most frequent ADRs observed during biological therapy in patients with IBD [18]. In our series, these ADRs were the most common (35\%), but only one was classified as severe and required hospitalization of the patient. All patients treated with IFX (both IFX-Remicade and IFXRemsima) received loratadine (10 $\mathrm{mg}$ ) before infusion, but nonetheless 9 IRRs occurred under IFX, representing 20\% of overall ADRs. These types of reactions related to the administration of biological drugs are still being studied, as often in randomized controlled trials they are investigated as a secondary outcome, and therefore are not detailed in the final analysis of the safety profile [12].

Although the action of the biological drugs on the immune system may predispose to a greater susceptibility towards infectious agents, in our case series no severe infections were recorded. These data agree with a recent meta-analysis that evaluated 44 trials conducted on the use of biological drugs in IBD, not showing a significant association with the risk of developing severe infections [19]. These data were further confirmed by another recent meta-analysis which assessed the efficacy and safety of ADA in UC patients [20]. A Spanish study conducted on 152 patients treated with IFX for IBD, with a 9-year follow-up, revealed only 11 cases of viral and/or bacterial infections that required hospitalization [21]. Another monocentric study involving 734 patients with IBD treated with IFX did not reveal statistically significant differences in infection rate compared with 666 IBD controls not treated with biologics. The authors found that the only independent factor for the greatest susceptibility to infections was the concomitant steroid therapy [22]. In our series, no patient was on concomitant steroid treatment and this could explain the absence of severe infections. A Korean study including 175 patients being treated with biologicals, of which 54 were suffering from IBD, showed a $6 \%$ rate of severe infections, without observing differences compared to the use of IFX or ADA [23]. Data from Australia and New Zealand on over 5,000 patients identified a severe infection rate of $2.2 \%$, including two cases of primary Varicella Zoster infection, thus emphasizing the importance of elective vaccination of naïve patients before starting the biological therapy [24]. Of note, in our series GOL did not cause any infections, in agreement with a Spanish study of a cohort of $33 \mathrm{UC}$ patients followed prospectively for one year [25]. It is acknowledged that exposure to biological agents significantly increases the risk of opportunistic infections in patients with IBD [19]. Three patients developed herpes virus reactivation, varicella zoster infection and fungal infection, respectively, which are considered as opportunistic infections. Despite the evidence of a dysregulation of the mucosal immune response in patients with IBD, there is no strong evidence of a systemic immune deficiency in the absence of concomitant therapy with immunomodulatory drugs [26]. None of the three abovementioned patients was taking steroids or thiopurines. There are few epidemiological data on the predisposing factors for the development of opportunistic infections in patients with IBD, and the variables mainly involved seem to be older age, malnutrition, associated comorbidities, total parenteral nutrition and intestinal surgery [27]. A recent Italian multicentric study documented 2 cases of fungal pneumonia and 2 herpes zoster reactivation among 136 IBD patients treated with VDZ [28]. An increased risk of developing herpes zoster and pneumonia in patients with IBD has been widely described in patients treated with anti-TNF $\alpha$, especially when in combination with steroids and thiopurines [29,30]. None of our patients developed tuberculosis, nor did they show a positivity at screening for contact with mycobacterium as assessed according to the guidelines [31].

In the context of ADRs induced by biological drugs, dermatological manifestations deserve special attention, as the skin appears to be one of the most frequently involved organs in ADRs occurrence during anti-TNF $\alpha$ therapy in patients with IBD [32]. We documented skin disorders in $20 \%$ of cases, including one atopic dermatitis and one psoriasiform dermatitis. There are numerous reports of skin involvement during anti-TNF $\alpha$ therapy, including 
new psoriasis onset or exacerbation during therapy, vasculitis or lupus, skin infections and neoplasms, and of course injection-site reactions, both acute and delayed [33]. Nevertheless, the risk factors for adverse skin events have not yet been fully identified in patients with IBD who undergo anti-TNF $\alpha$ therapy, considering that the incidence of cutaneous manifestations is between 2 and $34 \%$ as extraintestinal manifestations of the disease [34]. In the large cohort analyzed by a Portuguese study for a period of 10 years, among 732 patients with IBD treated with anti-TNF $\alpha$ agents, 211 (29\%) developed at least one dermatological complication [35]. Some patients presented idiosyncratic reactions on an allergic basis, while other dermatological ADRs were a consequence of immunosuppression (for example, infections and cancer), or seemed to be a consequence of the alteration in inflammatory cytokine balance under TNF $\alpha$ inhibition (e.g. in the case of psoriasis) ${ }^{[33]}$. However, there is little knowledge of the risk factors associated with the development of dermatological complications in patients with IBD treated with anti-TNF $\alpha$ [36].

Five (11\%) patients developed ADRs classified as musculoskeletal disorders: 4 patients reported diffuse arthralgias and 1 reported a myalgia. The phenomenon of paradoxical arthritis that arises during anti-TNF $\alpha$ therapy in patients with IBD is of great interest in the scientific community [37]. In fact, joint manifestations are called paradoxes when they occur during treatment with anti$\mathrm{TNF} \alpha$ since this type of medication is approved for their treatment [38]. Up to $10 \%$ of patients who develop paradoxical arthritis during anti-TNF $\alpha$ therapy are forced to discontinue therapy [39]. In our case series, none of the 5 patients with development of musculoskeletal disorders discontinued therapy, these ADRs being classified as mild. The mechanisms related to these paradoxical manifestations are still unclear [40].

For 2 patients who developed leukopenia, the discontinuation of the biological drug was necessary; however, hematological values returned to normal a short time after stopping biological therapy. Biological therapies act directly on the inflammatory cascade, therefore their immunosuppressive mechanism can determine alterations in the white blood cell count or myelo-suppression [41]. Although this side effect is more investigated for thiopurine, leukopenia was documented also during anti-TNF therapy [42].

Regarding the risk of lymphoproliferative diseases and neoplasms, the literature data are often conflicting, in part due to heterogeneity of studies [43]. There have been no cases of malignancy in our population during a twoyear period. The presence of selection and detection bias is frequently a limiting factor in clinical trials, and this could overestimate the risk of cancer in IBD during biologic therapy. On the contrary, population studies on cohorts of unselected patients are more representative of the real risk of cancer in patients with IBD and, therefore, lend themselves to the acquisition of prognostic information and risk estimates $[44,45]$. A recent meta-analysis comprising 23 studies, for a total of 9455 patients, did not reveal a significant increase in cancer risk in patients with IBD treated with anti-TNF $\alpha$ [19]. In a recent Danish cohort study conducted on 56,146 patients with IBD, the use of anti-TNF $\alpha$ was not associated with an increased risk of hematological malignancies [46]. Reassuring data also come from studies conducted on pediatric populations, which show that exposure to IFX is not associated with the development of neoplasms or hematological disorders [47]. Also, with regard to skin tumors, from the data in the literature it can be assumed that biological drugs do not predispose to a greater risk [48]. Although an increased frequency of hematological cancers was reported in a study conducted in Minnesota on 122 patients treated with biologics, the data were not statistically significant [49].

\section{Conclusions}

The safety and tolerability of biological drugs in IBD is widely investigated. However, the precise interactions of this class of drugs with the immune system have not yet been fully understood, making it difficult to predict the occurrence and the severity of ADRs. In the cohort of patients with IBD treated with biological drugs, observed in our Unit, ADRs have been frequent, but in most cases were mild. Most ADRs were recorded during the infusion of IFX. However, if we consider the number of patients treated with each drug, GOL was the most frequently associated with the occurrence of ADRs, albeit mild. In contrast, VDZ presented the lowest risk of triggering ADRs. As regards the comparison between the forms of IFX currently on the market, the security of the biosimilar Remsima (CT-P13) is comparable to that of the originator in our series. There were no cases of lymphoproliferative diseases and malignancies in the enrolled patients. Finally, only 9 ADRs made it necessary to permanently discontinue the drug. No ADRs resulted in the death or the occurrence of permanent disabilities. Consequently, it is possible to conclude that the results of our study are in line with the data from the available studies on the safety of biological drugs. Pharmacovigilance programs are important to report the clinical practice experience during the post-marketing phase, thereby providing clinicians with data reflecting a daily reality.

\section{References}

1. Martínez-Montiel MP, Casis-Herce B, Gómez-Gómez GJ, Masedo-González A, Yela-San Bernardino C, Piedracoba C, et al. Pharmacologic therapy for inflammatory bowel disease refractory to steroids. Clin Exp Gastroenterol. 2015;8:257269.

2. Singh S, Fumery M, SandbornW J, Murad MH. Systematic 
review and network meta-analysis: first- and second-line biologic therapies for moderate-severe Crohn's disease. Aliment Pharmacol Ther. 2018;48:394-409.

3. Sabino J, Verstockt B, Vermeire S, Ferrante M. New biologics and small molecules in inflammatory bowel disease: an update. Therap Adv Gastroenterol. 2019;12:1756284819853208.

4. Ma C, Panaccione NR, Nguyen TM, Guizzetti L, Parker CE, Hussein IM, et al. Adverse Events and Nocebo Effects in Inflammatory Bowel Disease: A Systematic Review and Meta-Analysis of Randomized Controlled Trials. J Crohns Colitis. 2019;13:1201-1216.

5. Shivaji UN, Sharratt CL, Thomas T, Smith SCL, Iacucci M, Moran GW, et al. Review article: managing the adverse events caused by anti-TNF therapy in inflammatory bowel disease. Aliment Pharmacol Ther. 2019;49:664-680.

6. Roberti R, Iannone LF, Palleria C, De Sarro C, Spagnuolo $\mathrm{R}$, Barbieri MA, et al. Safety profiles of biologic agents for inflammatory bowel diseases: a prospective pharmacovigilance study in Southern Italy. Curr Med Res Opin. 2020;36:1457-1463.

7. Bae JM, Lee HH, Lee BI, Lee KM, Eun SH, Cho ML, et al. Incidence of psoriasiform diseases secondary to tumour necrosis factor antagonists in patients with inflammatory bowel disease: a nationwide population-based cohort study. Aliment Pharmacol Ther. 2018;48:196-205.

8. Moćko P, Kawalec P, Pilc A. Safety Profile of Biologic Drugs in the Treatment of Inflammatory Bowel Diseases: A Systematic Review and Network Meta-analysis of Randomized Controlled Trials. Clin Drug Investig. 2017;37:25-37.

9. Spekhorst LM, Visschedijk MC, Alberts R, Festen EA, van der Wouden EJ, Dijkstra G, et al. Performance of the Montreal classification for inflammatory bowel diseases. World J Gastroenterol. 2014;20:15374-15381.

10. Cheifetz A, Smedley M, Martin S, Reiter M, Leone G, Mayer $\mathrm{L}$, et al. The incidence and management of infusion reactions to infliximab: a large center experience. Am J Gastroenterol 2003;98:1315-1324.

11. Singh S, Fumery M, Sandborn WJ, Murad MH. Systematic review with network meta-analysis: first- and second-line pharmacotherapy for moderate-severe ulcerative colitis. Aliment Pharmacol Ther. 2018;47:162-175.

12. Lichtenstein L, Ron Y, Kivity S, Ben-Horin S, Israeli E, Fraser GM, et al. Infliximab-Related Infusion Reactions: Systematic Review. J Crohns Colitis. 2015;9:806-815.

13. D'Haens GR, Sartor RB, Silverberg MS, Petersson J, Rutgeerts P. Future directions in inflammatory bowel disease management. J Crohns Colitis. 2014;8:726-734.

14. Colombel JF, Loftus EV Jr, Tremaine WJ, Egan LJ, Harmsen WS, Schleck CD, et al. The safety profile of infliximab in patients with Crohn's disease: the Mayo clinic experience in 500 patients. Gastroenterology. 2004;126:19-31.

15. Tursi A, Mocci G, Faggiani R, Allegretta L, Valle ND, Forti $\mathrm{G}$, et al. Infliximab biosimilar CT-P13 is effective and safe in treating inflammatory bowel diseases: a real-life multicenter, observational study in Italian primary inflammatory bowel disease centers. Ann Gastroenterol. 2019;32:392-399.
16. Ibraheim H, Samaan MA, Srinivasan A, Brain O, Digby-Bell J, Irving PM, et al. Effectiveness and safety of vedolizumab in inflammatory bowel disease patients aged 60 and over: an observational multicenter UK experience. Ann Gastroenterol. 2020;33:170-177.

17. Tursi A, Allegretta L, Buccianti N, Della Valle N, Elisei W, Forti G, et al. Effectiveness and Safety of Golimumab in Treating Outpatient Ulcerative Colitis: A Real-Life Prospective, Multicentre, Observational Study in Primary Inflammatory Bowel Diseases Centers. J Gastrointestin Liver Dis. 2017;26:239-244.

18. O'Meara S, Nanda KS, Moss AC. Antibodies to infliximab and risk of infusion reactions in patients with inflammatory bowel disease: a systematic review and meta-analysis. Inflamm Bowel Dis. 2014;20:1-6.

19. Bonovas S, Fiorino G, Allocca M, Lytras T, Nikolopoulos GK, Peyrin-Biroulet L, et al. Biologic Therapies and Risk of Infection and Malignancy in Patients With Inflammatory Bowel Disease: A Systematic Review and Network Metaanalysis. Clin Gastroenterol Hepatol. 2016;14:1385-1397. e10.

20. Zhang ZM, Li W, Jiang XL. Efficacy and Safety of Adalimumab in Moderately to Severely Active Cases of Ulcerative Colitis: A Meta-Analysis of Published PlaceboControlled Trials. Gut Liver. 2016;10:262-274.

21. Zabana Y, Domènech E, Mañosa M, Garcia-Planella E, Bernal I, Cabré E, et al. Infliximab safety profile and longterm applicability in inflammatory bowel disease: 9-year experience in clinical practice. Aliment Pharmacol Ther. 2010;31:553-560.

22. Fidder H, Schnitzler F, Ferrante M, Noman M, Katsanos $\mathrm{K}$, Segaert S, et al. Long-term safety of infliximab for the treatment of inflammatory bowel disease: a single-centre cohort study. Gut. 2009;58:501-508.

23. Yoo IK, Choung RS, Hyun JJ, Kim SY, Jung SW, Koo JS, et al. Incidences of serious infections and tuberculosis among patients receiving anti-tumor necrosis factor- $\alpha$ therapy. Yonsei Med J. 2014;55:442-448.

24. Lawrance IC, Radford-Smith GL, Bampton PA, Andrews JM, Tan PK, Croft A, et al. Serious infections in patients with inflammatory bowel disease receiving anti-tumor-necrosisfactor-alpha therapy: an Australian and New Zealand experience. J Gastroenterol Hepatol. 2010;25:1732-1738.

25. Bosca-Watts MM, Cortes X, Iborra M, Huguet JM, Sempere L, Garcia G, et al. Short-term effectiveness of golimumab for ulcerative colitis: Observational multicenter study. World J Gastroenterol. 2016;22:10432-10439.

26. Beaugerie L, Rahier JF, Kirchgesner J. Predicting, Preventing, and Managing Treatment-Related Complications in Patients With Inflammatory Bowel Diseases. Clin Gastroenterol Hepatol. 2020;18:1324-1335.e2.

27. Ananthakrishnan AN, McGinley EL. Infection-related hospitalizations are associated with increased mortality in patients with inflammatory bowel diseases. J Crohns Colitis. 2013;7:107-112.

28. Tursi A, Mocci G, Faggiani R, Allegretta L, Valle ND, Medici A, et al. Vedolizumab is effective and safe in reallife treatment of inflammatory bowel diseases outpatients: 
A multicenter, observational study in primary inflammatory bowel disease centers. Eur J Intern Med. 2019;66:85-91.

29. Long MD, Martin C, Sandler RS, Kappelman MD. Increased risk of herpes zoster among 108604 patients with inflammatory bowel disease. Aliment Pharmacol Ther. 2013;37:420-429.

30. Long MD, Martin C, Sandler RS, Kappelman MD. Increased risk of pneumonia among patients with inflammatory bowel disease. Am J Gastroenterol. 2013;108:240-248.

31. Lamb CA, Kennedy NA, Raine T, Hendy PA, Smith PJ, Limdi JK, et al. British Society of Gastroenterology consensus guidelines on the management of inflammatory bowel disease in adults. Gut. 2019;68(Suppl 3):s1-s106.

32. Mocci G, Marzo M, Papa A, Armuzzi A, Guidi L. Dermatological adverse reactions during anti-TNF treatments: focus on inflammatory bowel disease. J Crohns Colitis. 2013;7:769-779.

33. Torres J, Buche S, Delaporte E, Colombel JF. Skin side effects of inflammatory bowel disease therapy. Inflamm Bowel Dis. 2013;19:1086-1098.

34. Greuter T, Navarini A, Vavricka SR. Skin Manifestations of Inflammatory Bowel Disease. Clin Rev Allergy Immunol. 2017;53:413-427.

35. Andrade P, Lopes S, Gaspar R, Nunes A, Magina S, Macedo G. Anti-Tumor Necrosis Factor- $\alpha$-Induced Dermatological Complications in a Large Cohort of Inflammatory Bowel Disease Patients. Dig Dis Sci. 2018;63:746-754.

36. Hellström AE, Färkkilä M, Kolho KL. Infliximab-induced skin manifestations in patients with inflammatory bowel disease. Scand J Gastroenterol. 2016;51:563-571.

37. Sondag M, Verhoeven F, Guillot X, Prati C, Briot C, Vuitton $\mathrm{L}$, et al. "Paradoxical" arthralgia occurring under anti-TNF $\alpha$ treatment for inflammatory bowel disease. Joint Bone Spine. 2018;85:133-134.

38. Brakenhoff LK, van der Heijde DM, Hommes DW, Huizinga TW, Fidder HH. The joint-gut axis in inflammatory bowel diseases. J Crohns Colitis. 2010;4:257-268.

39. Schnitzler F, Fidder H, Ferrante M, Noman M, Arijs I, Van Assche G, et al. Long-term outcome of treatment with infliximab in 614 patients with Crohn's disease: results from a single-centre cohort. Gut. 2009;58:492-500.

40. Cleynen I, Vermeire S. Paradoxical inflammation induced by
anti-TNF agents in patients with IBD. Nat Rev Gastroenterol Hepatol. 2012;9:496-503.

41. AlAskar D, AlSardi M, Al Sulais E, Mosli M, AlAmeel T. Risk of neutropenia in inflammatory bowel disease patients treated with TNF inhibitors: A single-center, retrospective cohort study. Saudi J Gastroenterol. 2020;26:210-215.

42. Tursi A, Elisei W, Faggiani R, Allegretta L, Valle ND, Forti $\mathrm{G}$, et al. Effectiveness and safety of adalimumab to treat outpatient ulcerative colitis: A real-life multicenter, observational study in primary inflammatory bowel disease centers. Medicine (Baltimore). 2018;97:e11897.

43. Kimmel J, Axelrad J. The Complex Interplay Between Inflammatory Bowel Disease and Malignancy. Curr Gastroenterol Rep. 2020;22:13.

44. Chen Y, Sun J, Yang Y, Huang Y, Liu G. Malignancy risk of anti-tumor necrosis factor alpha blockers: an overview of systematic reviews and meta-analyses. Clin Rheumatol. 2016;35:1-18.

45. Lichtenstein GR, Feagan BG, Cohen RD, Salzberg BA, Safdi M, Popp JW Jr, et al. Infliximab for Crohn's Disease: More Than 13 Years of Real-world Experience. Inflamm Bowel Dis. 2018;24:490-501.

46. Nyboe Andersen N, Pasternak B, Basit S, Andersson M, Svanström H, Caspersen S, et al. Association between tumor necrosis factor- $\alpha$ antagonists and risk of cancer in patients with inflammatory bowel disease. JAMA. 2014;311:24062413.

47. Hyams JS, Dubinsky MC, Baldassano RN, Colletti RB, Cucchiara S, Escher J, et al. Infliximab Is Not Associated with Increased Risk of Malignancy or Hemophagocytic Lymphohistiocytosis in Pediatric Patients with Inflammatory Bowel Disease. Gastroenterology. 2017;152:1901-1914.e3.

48. Scott FI, Mamtani R, Brensinger CM, Haynes K, ChiesaFuxench ZC, Zhang J, et al. Risk of Nonmelanoma Skin Cancer Associated with the Use of Immunosuppressant and Biologic Agents in Patients with a History of Autoimmune Disease and Nonmelanoma Skin Cancer. JAMA Dermatol. 2016;152:164-172.

49. Yadav S, Singh S, Harmsen WS, Edakkanambeth Varayil J, Tremaine WJ, Loftus EV Jr. Effect of Medications on Risk of Cancer in Patients with Inflammatory Bowel Diseases: A Population-Based Cohort Study from Olmsted County, Minnesota. Mayo Clin Proc. 2015;90:738-746. 